\title{
François Heinderyckx, La Malinformation
}

Paris, éditions Labor, 2002.

\section{Emilie Moreau}

\section{(2) OpenEdition}

\section{Journals}

Édition électronique

URL : http://journals.openedition.org/edc/138

DOI : $10.4000 /$ edc. 138

ISSN : 2101-0366

\section{Éditeur}

Université de Lille

Édition imprimée

Date de publication : 1 décembre 2003

Pagination : 182-183

ISSN : 1270-6841

Référence électronique

Emilie Moreau, «François Heinderyckx, La Malinformation », Études de communication [En ligne], 26 |

2003, mis en ligne le 13 octobre 2008, consulté le 22 septembre 2020. URL : http://

journals.openedition.org/edc/138; DOI : https://doi.org/10.4000/edc.138

Ce document a été généré automatiquement le 22 septembre 2020.

(c) Tous droits réservés 


\section{François Heinderyckx, $L a$ Malinformation}

Paris, éditions Labor, 2002.

Emilie Moreau

\section{RÉFÉRENCE}

François Heinderyckx, La malinformation

1 On connaissait le terme de malbouffe, inventé par Joël de Rosnay en 1979, on connaîtra désormais celui de malinformation, titre de ce court essai. François Heinderyckx entend ici montrer les effets pervers de la croissance exponentielle des sources et supports d'information observée depuis une dizaine d'année dans le monde occidental. On l'aura compris, on est ici loin des utopies du village global et de l'accès à l'information pour tous car « les efforts visant à générer et à organiser l'information se trouvent annihilés par le bouillonnement ambiant, par le développement anarchique de structures de production, de structuration, de recyclage ou simplement de stockage ou d'échange de l'information ». Se défendant d'un quelconque « dégoût » de ce que $\ln$ appelle communément les NTIC, l'auteur propose d'analyser les causes de ce phénomène qu'est la malinformation (que l'on aurait tort de confondre avec la surinformation qui n'est que la prolifération des informations). Les origines de ce mal sont clairement identifiables : la multiplication des sources, des supports, la « culture de la mise à jour permanente, du suivi en temps réel » qui empêchent la vérification, le regroupement, la réflexion et l'analyse, ainsi que la prise en compte toujours plus importante des goûts du public (qui a selon l'auteur une fâcheuse tendance à préférer les divertissements et l'infotainment) ont engendré un appauvrissement de la qualité des contenus rédactionnels (qui tendent de plus à l'uniformisation). En effet, le " discours journaliste, tous médias confondus, semble consacrer de plus en plus d'espace à la description des faits, jusque dans les détails insignifiants, alors que se raréfient les mises en perspective, les analyses, tout ce qui doit permettre au consommateur 
d'information de prendre du recul par rapport à l'événement, de le recadrer et de lui donner un sens ». Les journalistes préfèrent la concision et le récit de faits (divers, people, sportifs) à l'analyse profonde et fouillée de sujets plus graves (géopolitiques par exemple) qui nécessite plus de temps et d'efforts intellectuels de leur part et du public. Cependant, la malinformation ne concerne pas que les médias. Les notices de médicaments, modes d'emplois - qui sont parfois incompréhensibles - en sont également des exemples : les rédacteurs ne prennent pas en compte le fait que les usagers ne sont pas des spécialistes. La malinformation peut prendre des formes multiples (sondages, slogans) et concerner de nombreux domaines (politique, publicité...).

2 Certes il propose des solutions, mais celles ci sont exposées trop brièvement pour constituer un véritable programme de «lutte». Éduquer les enfants à la critique de l'appareil médiatique, "encourager l'information par une promotion du plaisir de savoir, mais surtout de comprendre ", redéfinir le rôle, les méthodes et tâches des journalistes semblent des alternatives envisageables. On peut reprocher à cet ouvrage, bien que ce soit le parti pris de l'auteur, l'absence de références et de bibliographie ainsi que le manque d'exemples précis tirés de supports médiatiques. 